\title{
Development of a Bikeability Index to Assess the Bicycle-Friendliness of Urban Environments
}

\author{
Patricia Jasmin Krenn', Pekka 0ja², Sylvia Titze ${ }^{1}$ \\ ${ }^{1}$ Institute of Sport Science, University of Graz, Graz, Austria \\ ${ }^{2}$ UKK Institute, Tampere, Finland \\ Email: patricia.krenn@gmx.net, pekka.oja@uta.fi, sylvia.titze@uni-graz.at
}

Received 5 October 2015; accepted 28 December 2015; published 31 December 2015

Copyright (C) 2015 by authors and Scientific Research Publishing Inc.

This work is licensed under the Creative Commons Attribution International License (CC BY). http://creativecommons.org/licenses/by/4.0/

cC) (7) Open Access

\begin{abstract}
Background: Cycling as a means of transport contributes to public health in terms of increasing the physical activity behaviour and reducing air pollution. In comparison to walking, cycling-specific environmental characteristics have been less investigated. The aim of this study was to develop, based on geographic information systems (GIS) data, a bikeability index for a mid-sized European city, to examine the predictive validity of the index and to visualize the bicycle-friendliness of the city by creating a bikeability map. Methods: Using GIS data, we assessed the environmental characteristics of $\mathbf{2 7 8}$ bicycle trips in the city of Graz, Austria. Characteristics which differed significantly between the actually taken and shortest possible routes were used to form an additive bikeability index and the bikeability map for $100 \mathrm{~m} \times 100 \mathrm{~m}$ cells. The relationship between the cycling behaviour and the bikeability index around the home environment was examined to assess the predictive validity of the index. Results: Three environmental components (cycling infrastructure, bicycle pathways and green areas) were positively related, and two components (main roads, and topography) were negatively related to the actually used route. These components formed the bikeability index, which was positively correlated with cycling behaviour (OR: 1.08, 95\% CI 1.01 - 1.17). The final outcome is a high-resolution coloured map indicating the degree of bicycle-friendliness in the city of Graz. Conclusion: Mapping based on the bikeability index helps to visualize the bicycle-friendliness of an urban area. Therefore, it should be a useful tool for the planning as well as for the evaluation of the transport environments in cities.
\end{abstract}

\section{Keywords}

Bicycling, Environment, Map, GIS, Active Mobility 


\section{Introduction}

Cycling can be seen as a potentially sustainable solution to improve public health, including a reduction in traffic and air pollution. A growing body of evidence demonstrates that the built environment correlates with cycling behaviour and those regions can be friendly to cyclists [1]-[6]. Features of bicycle-friendly neighbourhoods include bicycle lanes and bicycle pathways [1] [4] [7] [8], flat terrain [9]-[11], low traffic volume [4] [10] [12] and green as well as attractive areas [4] [5] [13]. For example, cities with more bicycle lanes seem to have higher cycling rates than cities with less bicycle lanes [1] [14] [15]. This suggests that changes in urban design may increase the level of cycling.

To summarize and quantify the activity-friendliness of different environments, researchers have developed various indices. The different environmental components that support or hinder physical activity are mathematically combined to create comparable index values. In the last decade, special emphasis has been placed on the creation of walkability indices [16]-[18]. The most-cited walkability index that describes the walking friendliness of regions was developed by Frank et al. in 2005 in Canada [17]. This original additive index included the component connectivity, land-use mix and population density. The components were calculated by the use of digital maps in a geographic information system (GIS). The walkability index of Frank et al. has also been used and slightly modified in a number of other research studies [19]-[21].

Less research time has been spent on the development of bikeability indices. However, two indices have been found which describe the bicycle-friendliness of street segments: 1) Eddy (1996)—-this index was first published in Emery et al. in 2003 [16]; and 2) Harkey et al. in 1998 [22]. Both indices are calculated in quite complex formulas, with many different components measured by audits. Eddy (1996) combined 27 different components of the categories "street condition", "road” and "street facilities" to quantify the cycling friendliness of a street segment. Harkey et al. (1998) combined and weighted nine different components to calculate a "bicycle compatibility index" of street segments.

In a recent study by Van Dyck et al. [23] a "cyclability index" was constructed for regions. It is based on perceived built environmental attributes that were associated with transport-related cycling in adult samples. This additive index was calculated for metropolitan areas in the USA, Australia and Belgium, and consists of the components' proximity to destinations, walking and cycling facilities, difficulties in parking near local shopping areas, and aesthetics, which were assessed using the neighbourhood environmental walkability scale (NEWS).

The disadvantage of indices that are based on questionnaires or audits is that the analysis for big areas is very time-consuming. The use of GIS-data allows semi-automatical calculation of indices for very large areas. To our knowledge, there exists only one bikeability index that used GIS-data to quantify the components [24]. This additive index consists of five components, namely, bike route density, bike route separation, connectivity, topography, and destination density. Apart from topography, it was assumed that all the components were positively related to cycling. This index was mapped in the city of Vancouver to detect bicycle-friendly areas and areas where the cycling conditions need to be improved. It is well adjusted to North American city design and offers a great opportunity to compare American cities based on the results of this index. In European cities, however, the urban street network conditions are not comparable to the rectangle street network in North America. Therefore an adjustment of the bikeability index of Winters et al. (2012) is necessary.

The aim of the present study was to develop, based on GIS data, a bikeability index for a mid-sized European city (Graz, Austria), to examine the predictive validity of the index, and to visualize the bikeability of the city by creating a bikeability map.

\section{Methods}

\subsection{Setting and Sample}

The study was conducted in the city of Graz (Austria), which has a population of almost 300,000 inhabitants and an area of about $130 \mathrm{~km}^{2}$. The city has a relatively large number of bike pathways, and the modal split for transport cycling is currently 14\%. The mild climate of Graz permits cycling almost throughout the year. The cycling infrastructure of Graz $(120 \mathrm{~km})$ consists of dedicated bike paths as well as bike lanes adjacent to streets. Besides, all side roads are subject to a speed limit of $30 \mathrm{~km} / \mathrm{h}$ (=19 miles/h) and are therefore quite attractive for cycling. Traffic signals for cyclists and pedestrians permit cyclists to use designated bike pathways and cross major roads safely. 
Participants were recruited from this "bicycle-friendly city", with a representative sample of 1000 participants [3]. In 2005, 80 study participants from this sample drew their most frequent bicycle trip on a map. In 2010, 70 members of the large sample were asked to wear a GPS data logger for four days in order to record their daily trips. Forty-eight of the 70 participants used their bikes as a means of transportation, and were included in the analysis. Fifteen persons participated in both bicycling studies. Thus, data concerning 113 participants $(80-15$ +48 ) were available for analysis and were used to identify the differences in distance and built environment between actually used and shortest possible routes. The 113 participants consisted of more women than men (55\% vs. $45 \%$ ). A total of $40 \%$ were younger than 35 years of age, $40 \%$ were between 35 and 50 years, and $20 \%$ were older than 51 years.

\subsection{Identification of the Components of the Bikeability Index}

Finally, 278 different actual bike trips of the 113 participants were used to investigate the route choices of the cyclists. The detailed study design and methods are described elsewhere [6]. In total, we compared the prevalence of 18 environmental characteristics along the actually used and the shortest possible route. The characteristics which were significantly different between the two routes were used as components to form the additive bikeability index. These components were cycling infrastructure, presence of separated bicycle pathways, main roads without parallel bicycle lanes, green and aquatic areas, topography, and land-use mix.

\subsection{Predictive Validity of the Bikeability Index}

The predictive validity of the bikeability index was examined by correlating the bikeability index with the cycling behaviour. The address data (831 out of 1000 were available) and mobility information were obtained from the "bicycle-friendly city" study [3] and combined with the calculated bikeability index in a GIS. Persons who cycled at least three times per week in the warm season were defined as cyclists ( $\mathrm{n}=402$ out of 831). The living neighbourhood was defined as the $1 \mathrm{~km}$ surrounding area around the home address (circular buffer). Mean bikeability values were calculated for each home address neighbourhood using digital maps. Details of the assessment of the components for the bikeability index are described in the "mapping bikeability" section. Digital maps were acquired from administrative institutions and from the Open Street Map portal. Mann-Whitney U-tests were applied to find the differences between the two cycling groups, and a logistic regression model was applied to test the association between bicycle-friendliness in the neighbourhood and cycling, while controlling the socio-demographic factors of gender (female/male), age ( $<40$ years, $\geq 40$ years) and education (general qualification for university entrance or not). The bikeability index had a metric scale.

\subsection{Mapping Bikeability}

The bikeability index was calculated in small areas in order to create a continuous high-resolution map for the whole city. Graz was therefore divided into $100 \mathrm{~m} \times 100 \mathrm{~m}$ cells, where each cell represented one bikeability value. The bikeability index was calculated for each cell buffered by $200 \mathrm{~m}$, to also take the bicycle-friendliness of the surrounding $100 \mathrm{~m} \times 100 \mathrm{~m}$ cells into account and to avoid sharp boundaries (Figure 1). The distance from the quadratic cell centre to the end of the buffer was at least $250 \mathrm{~m}$. This distance resulted from our previous research, as the average distance that cyclists detoured [6] was $250 \mathrm{~m}$.

The environmental components of the bikeability index were calculated using digital data maps in Quantum GIS 1.6 and ArcGIS 9.1 GIS software. The bicycling infrastructure in the cell and its buffer was defined as the total length of all the bicycle infrastructure (separated bicycle pathways and bicycle lanes along streets). The dataset of the separated bicycle pathways exists twice in the formula as the second component, and was defined as the length of all the separated bicycle pathways. Following the components of the cycling infrastructure, the component of the main roads was calculated by assessing the length of all the main roads without parallel bicycle lanes.

For the green and aquatic features, the surface area was calculated in each cell and cell buffer. The slopes of the topography data layer were defined in slope classes, where class 1 was the least and class 7 the most hilly. For the component topography, the mean slope class value within the cell and its buffer was used. Land-use mix was calculated according to the definition proposed by Frank et al. [17]. We included four types of land use: residential areas, industrial areas, circulation areas, and green and aquatic areas. The index ranges from 0 to $1 ; 0$ stands for only one land-use type while 1 indicates a well-distributed land-use area. 


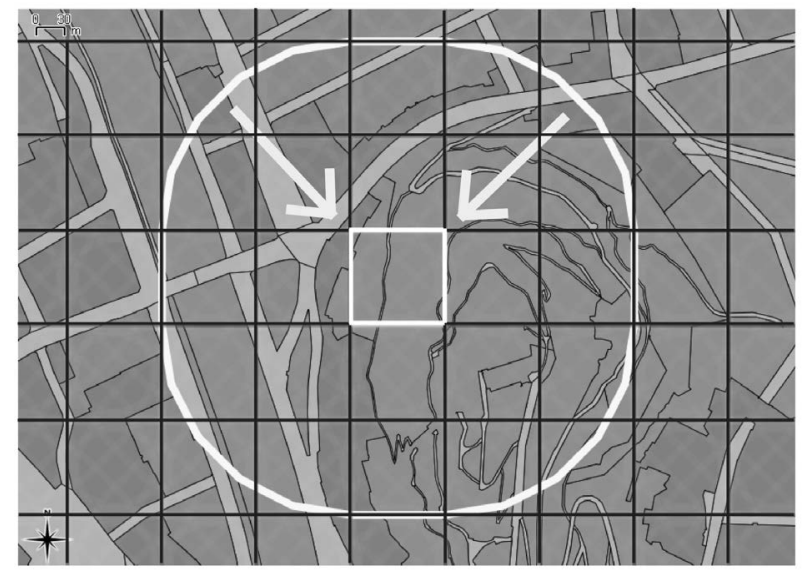

Figure 1. Calculation of the bikeability index for one cell in the $200 \mathrm{~m}$ cell buffer (Geodata: Stadtvermessungsamt Graz).

With the exception of the "separated bike pathways" component, the calculated component values for each cell were reclassified into deciles with a scale from 1 to 10. The presence of separated bicycle pathways was handled as a binary: scale 1 (less than $10 \mathrm{~m}$ of separated bicycle pathways), scale 10 (at least $10 \mathrm{~m}$ of separated bicycle pathways in the buffer). According to the formula of the bikeability index, the component scores were added to the final bikeability index. In the style of Winters et al. [24], colours were used to visualize the different bikeability values. Green indicates bicycle-friendly conditions, yellow moderate, and red indicates poor cycling conditions.

To simplify the interpretation of the bikeability map and to detect locations where cycling conditions need to be improved, an additional layer was generated in the GIS. This additional data layer is overlaid on the bikeability map and only shows the bikeability of relevant areas, i.e., areas that are connected to the street network. The other cells (with less than $10 \mathrm{~m}$ of streets) are covered by the mask coloured in grey. It was assumed that the interpretation of the cycling conditions in areas without streets connected to the street network was not feasible since every house is connected to the street network.

\section{Results}

\subsection{Bikeability Index}

Six environmental characteristics were chosen as the components of the bikeability index for a region: overall cycling infrastructure, presence of separated bicycle pathways, main roads without any parallel bicycle infrastructure, green and aquatic areas, topography, and land-use mix. After the first calculation of the bikeability index, the component of land-use mix was omitted because it did not change the final results in Graz. Finally, the bikeability index comprised five components:

Bikeability index $=$ cycling infrastructure + presence of separated bicycle pathways + main roads without parallel bicycle lanes + green and aquatic areas + topography

\subsection{Predictive Validity of the Bikeability Index}

The logistic regression showed a positive relationship between the bikeability index and the cycling behaviour, controlled for sex, age and education. The more bicycle-friendly a neighbourhood, the higher the chance of being a cyclist (OR: 1.08, 95\% CI: 1.01 - 1.17). If the bikeability value increased by one unit, the odds for cyclists in this neighbourhood increased by $8 \%$. The interaction between sex, age, education and the bikeability index was statistically insignificant.

\subsection{Bikeability Map}

The results of the scoring of the five components (in deciles) in the buffers of the $100 \mathrm{~m} \times 100 \mathrm{~m}$ cells in Graz are listed in Table 1 , where 1 is bicycle-unfriendly and 10 very bicycle-friendly. 
Table 1. Reclassification of the five environmental components in deciles ( 1 = bicycle-unfriendly, 10 = bicycle-friendly).

\begin{tabular}{|c|c|c|c|c|c|}
\hline Scores & Cycling infrastructure ${ }^{\mathrm{a}}[\mathrm{m}]$ & $\begin{array}{l}\text { Bicycle pathways } \\
\text { [0: no, 1: yes] }\end{array}$ & Main roads $[\mathrm{m}]$ & $\begin{array}{c}\text { Green and aquatic } \\
\text { areas }\left[\mathrm{m}^{2}\right]\end{array}$ & $\begin{array}{c}\text { Topographyc } \\
\text { [mean slope class] }\end{array}$ \\
\hline 1 & 0 & 0 & $1101-3565$ & $0-9955$ & 6 \\
\hline 2 & $1-251$ & - & $884-1100$ & $9956-18,241$ & 5 \\
\hline 3 & $252-430$ & - & $727-883$ & 18,242 - 29,039 & - \\
\hline 4 & $431-545$ & - & $586-726$ & $29,040-43,163$ & 4 \\
\hline 5 & $546-702$ & - & $492-585$ & $43,164-60,693$ & - \\
\hline 6 & $703-874$ & - & $406-491$ & $60,694-81,508$ & 3 \\
\hline 7 & $875-1063$ & - & $289-405$ & $81,509-108,159$ & - \\
\hline 8 & $1064-1314$ & - & $161-288$ & $108,160-139,712$ & 2 \\
\hline 9 & $1315-1645$ & - & $1-160$ & 139,713 - 161,999 & - \\
\hline 10 & $1646-3353$ & 1 & 0 & $>162,000$ & 1 \\
\hline
\end{tabular}

${ }^{\mathrm{a}}$ Separated bicycle pathways and bicycle lanes; ${ }^{\mathrm{b}}$ Main roads without any parallel bicycle infrastructure; ${ }^{\mathrm{c}}$ Slope class 1 is flat terrain.

The final bikeability indices for all the cells are mapped for the whole city. The bikeability map provides an overview of local cycling conditions. Moreover, the five individual components are mapped to better understand the final scoring of the bikeability in the region (Figure 2).

The result of the bikeability map overlaid with a grey mask (visualizing areas without streets) and plotted district boundaries is shown in Figure 3. Coloured bicycle-friendliness is only shown in areas that are connected to the street network. Cells with no connection to the street network are grey.

\section{Discussion}

The developed bikeability index was based on five key components which were correlated to cycling: cycling infrastructure, presence of separated bicycle pathways, main roads without any parallel bicycle infrastructure, aesthetic areas, and topography. The bikeability index was positively correlated with the cycling behaviour in the city of Graz. The final outcome was a high-resolution coloured map indicating the degree of bicycle-friendliness in different areas of the city.

The intention was to develop a simple bikeability index for European urban environments. As a comparable index was developed by Winters et al., we first compared our findings from the bivariate analysis with the findings of Winters et al. [24]. In both studies bicycle infrastructure as well as flat topography showed a positive relationship with cycling. The results of Van Dyck et al. also confirmed that good cycling facilities are positively related to cycling [23]. The results of Broach et al. suggested that cyclists are sensitive to slope and appear to place relatively high value on off-street bike paths [25]. The agreement for these variables in the different studies is very high. However, a contradiction between the results of Winters et al. [24] and our study was found regarding connectivity and destination density. These results may reflect the different urban street network conditions in Europe and Canada. Due to the inconsistent results and the insufficient evidence for European urban environments, none of these variables were used for developing our bikeability index. The "main roads without any parallel bicycle infrastructure" variable was kept due to the fact that cyclists avoiding main roads and high traffic areas was also found in other scientific studies [10] [12] [25] [26], and this variable can be considered to be negatively associated with cycling. Green and aquatic areas did not appear as a component in the bikeability index of Winters et al. [24] but were significantly positively related to cycling in Graz and in other studies [4] [5] [23]. Therefore, we added this variable to the potential components of our index. Based on the findings of Dill we decided to keep the land-use mix variable in the first iteration [27]. In order to keep the index simple, the remaining components were combined additively but the "separated bike pathways" component had a weight of 2 because it appeared in the bikeability index twice (general bicycle infrastructure and separated bike pathways). The cyclability index of Van Dyck et al. included the "perceiving difficulties in parking near local shopping areas" component [23]. Because this component cannot be measured objectively with GIS data, it was not included in our index. 


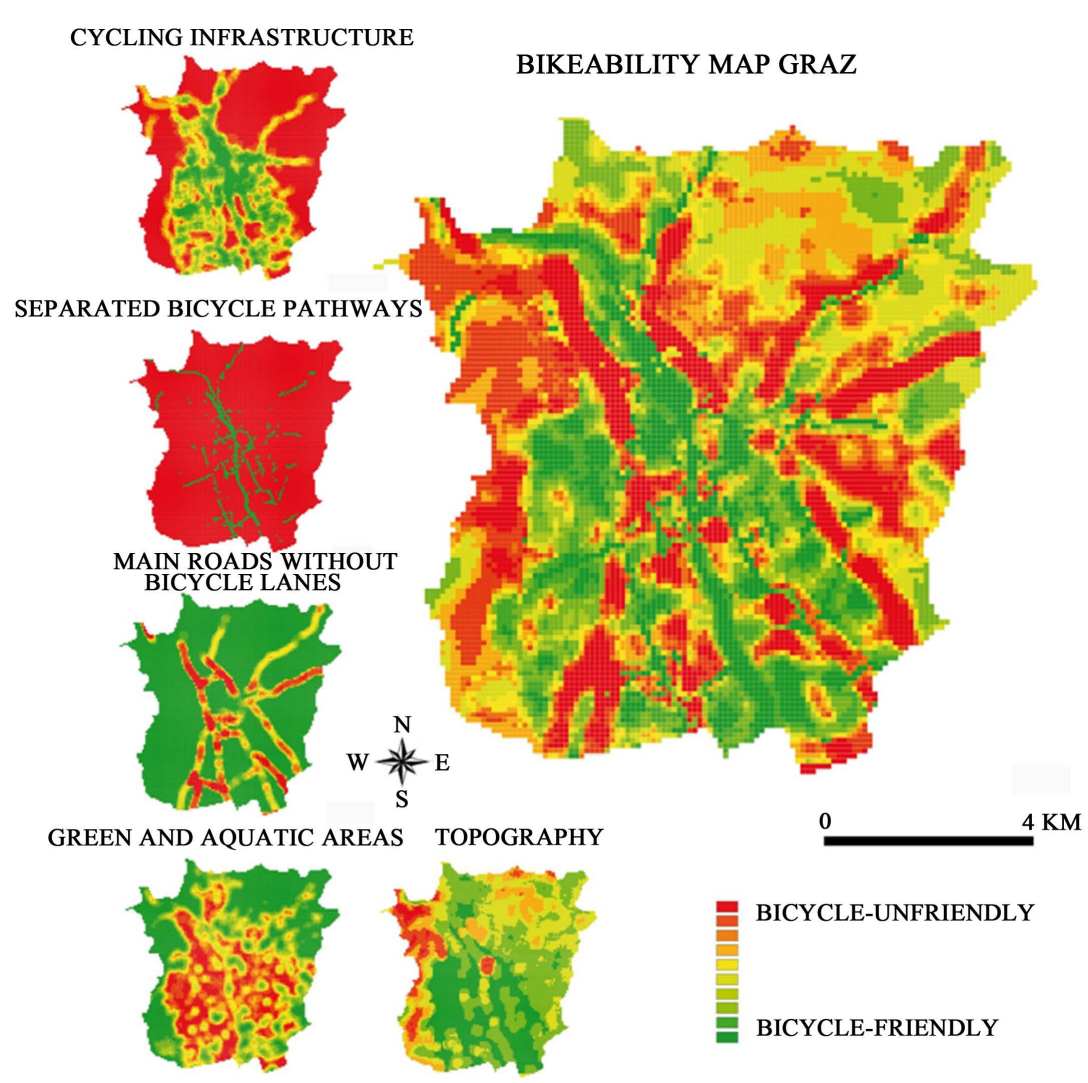

Figure 2. Mapped components of the bikeability index and the final bikeability map for the city of Graz (Geodata: Stadtvermessungsamt Graz).

BIKEABILITY MAP GRAZ

FOR AREAS CONNECTED TO THE STREET NETWORK

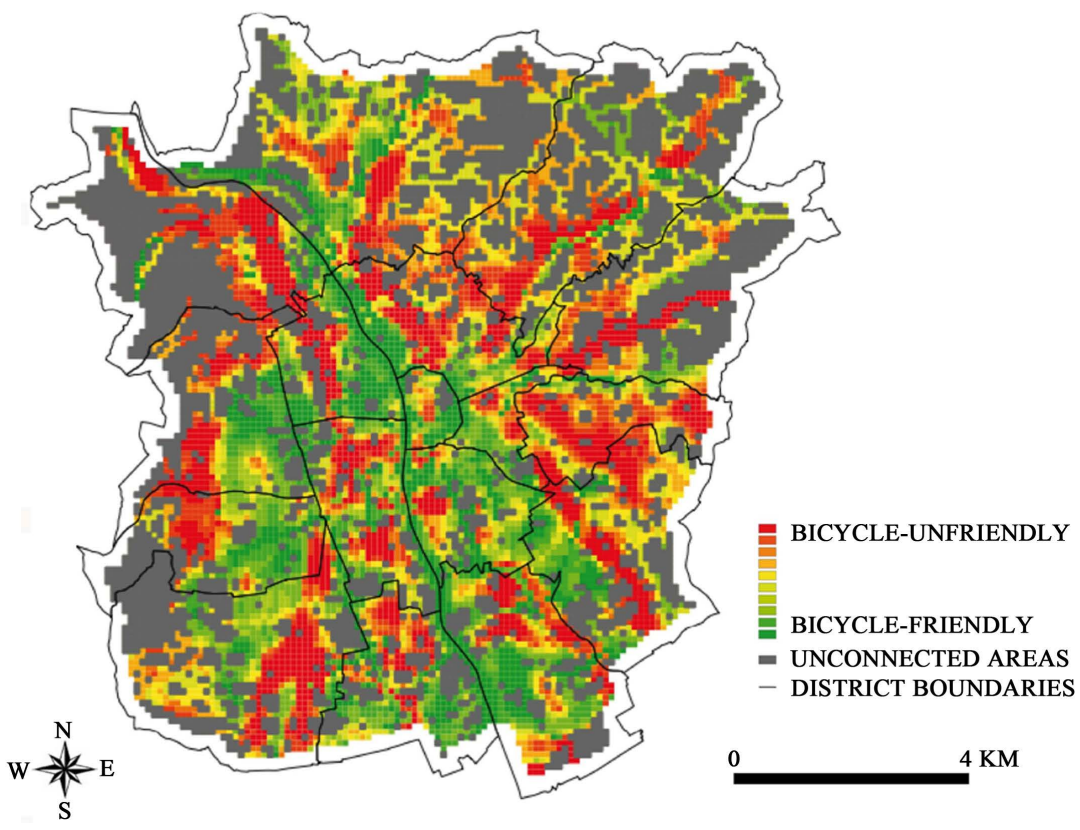

Figure 3. Bicycle-friendliness in urban areas in Graz, connected to the street network (Geodata: Stadtvermessungsamt Graz). 
The statistical regression analysis showed that regular cyclists live in more bicycle-friendly neighbourhoods (according to the bikeability index) than non-cyclists. Charreire et al. found that subjects residing in neighbourhoods characterized by high accessibility to green areas and local facilities and by a high density of cycle paths in Paris, France, were more likely to walk and cycle compared to those with a poor accessibility to green areas and facilities and an absence of cycle paths, after adjustment for individual and neighbourhood socio-demographic characteristics (OR: 2.5, 95\% CI: 1.4 - 4.6) [28]. This association is important information, especially for city planners and policy makers, in that the built environment may support people to use the bicycle for transportation. It is not known whether cyclists deliberately choose bicycle-friendly living neighbourhoods, or if improvements to the bicycle-friendliness of a region increase the cycling rate. To answer the latter, measurements before and after changes in urban design are required. "Natural experiments" are a great opportunity to study the impact of such changes, on the condition that the researchers are informed well in advance about the planned changes.

The bikeability map for Graz shows that the conditions for cyclists vary considerably between neighbourhoods. While the inner city and the areas along the river from north to south score high (=green), zones in the outer city generally have lower scores for good bikeability (=red). In the outer districts more cells are covered with the grey mask (see Figure 3). These areas are not connected to the street network, and there is therefore no special emphasis to improve the cycling conditions.

The bikeability map in Vancouver also showed that there is variability between neighbourhoods within the city [24]. Similar to Graz, the downtown area scored well, but the outer city districts had lower scores, especially for bicycle facilities. The authors argue that the developed map suggests that area-specific strategies should be considered. The cyclability index of Van Dyck et al. was not mapped, so the variability within the cities could not be studied and compared with our results [23].

For the interpretation of the bikeability map in Graz it is important to understand that the score for one cell represents the bicycling-friendliness of the cell and its $200 \mathrm{~m}$ surroundings. Therefore, the bikeability map is useful when answering questions like: how bicycle-friendly is it along street $x x$ or around squarexy? However, questions that are locally too limited cannot be answered properly with the bikeability map, e.g., how bicyclefriendly is the squareincellxy?

\section{Strengths and Limitations}

The components of the bikeability index have been empirically derived from objectively assessed environments along actually used routes. Only a small number of cycling-related environmental characteristics are required to create an informative bikeability index, and the GIS data for these components are widely available, allowing bikeability maps to be easily produced in other regions. One limitation of the study is that the results of a cross-sectional study do not allow conclusions to be drawn about the bikeability being a cause of cycling. Another limitation is the dependency on digital data maps. The digital map layers were collected from different sources and did not have the same quality and actuality. To produce a timeline of the bikeability in a city, actual digital data in short time intervals would be necessary. Unfortunately, digital data maps are not updated after each change of the built environment, and manual updating therefore becomes essential.

\section{Conclusion}

The bikeability index summarizes the urban environmental conditions for cycling. It consists of five components, and the GIS data for the components are widely available. The bikeability index is related to cycling behaviour, and the resulting mapping of the bikeability is a powerful tool for detecting areas where the cycling conditions need to be improved. The map is used like any other GIS-layer; it is possible to zoom in and to combine it with other spatial administrative data. The bikeability map can be a planning as well as an evaluation tool for the development of bicycle-friendly transport environment, particularly in European cities.

\section{Acknowledgements}

The first author was supported by the Young Scientists' Fund of Styria from November 2009 to October 2011. She received a scholarship of the Coordination Office of Gender Studies, Women's Research and Promotion of Women, from February 2012 to September 2012, and financial support from the Institute of Sports Science as 
well as from the Faculty of Environmental, Regional and Educational Sciences. Financial support for the GPS devices was provided by the Styrian provincial government. GIS data was provided by the department of GIS-Styria, and the city surveying department of Graz.

\section{Authors' Contributions}

PK conducted the study, derived the bikeability index, executed the GIS analysis and prepared the manuscript. ST made substantial contributions to the conception and design of the study, analysis and interpretation of data and drafting of the manuscript. PO was involved in the conception and interpretation of the study results and revised the manuscript for important intellectual content.

\section{References}

[1] Dill, J. and Carr, T. (2003) Bicycle Commuting and Facilities in Major U.S. Cities: If You Build Them, Commuters Will Use Them. Transportation Research: Part B, 1828, 116-123. http://dx.doi.org/10.3141/1828-14

[2] Wendel-Vos, G.C.W., et al. (2004) Factors of the Physical Environment Associated with Walking and Bicycling. Medicine \& Science in Sports \& Exercise, 36, 725-730. http://dx.doi.org/10.1249/01.MSS.0000121955.03461.0A

[3] Titze, S., et al. (2008) Association of Built-Environment, Social-Environment and Personal Factors with Bicycling as a Mode of Transportation among Austrian City Dwellers. Preventive Medicine, 47, 252-259. http://dx.doi.org/10.1016/j.ypmed.2008.02.019

[4] Wahlgren, L., et al. (2012) Exploring Bikeability in a Metropolitan Setting, Stimulating and Hindering Factors in Commuting Route Environments. TBMC Public Health, 12, 168. http://dx.doi.org/10.1186/1471-2458-12-168

[5] Beenackers, M.A., et al. (2012) Taking up Cycling after Residential Relocation, Built Environment Factors. American Journal of Preventive Medicine, 42, 610-615. http://dx.doi.org/10.1016/j.amepre.2012.02.021

[6] Krenn, P., Oja, P. and Titze, S. (2013) Route Choices of Transport Cyclists, Comparison of Actually Used and Shortest Routes. IJBNPA, 11, 31.

[7] Cervero, R., et al. (2009) Influences of Built Environments on Walking and Cycling, Lessons from Bogota. International Journal of Sustainable Transportation, 3, 203-226. http://dx.doi.org/10.1080/15568310802178314

[8] Beenackers, M.A., et al. (2012) Taking up Cycling after Residential Relocation, Built Environment Factors. American Journal of Preventive Medicine, 42, 610-615. http://dx.doi.org/10.1016/j.amepre.2012.02.021

[9] Rietveld, P. and Daniel, V. (2004) Determinants of Bicycle Use: Do Municipal Policies Matter? Transportation Research Part A-Policy and Practice, 7, 531-550. http://dx.doi.org/10.1016/j.tra.2004.05.003

[10] Parkin, J., et al. (2008) Estimation of the Determinants of Bicycle Mode Share for the Journey to Work Using Census Data. Transportation, 35, 93-109. http://dx.doi.org/10.1007/s11116-007-9137-5

[11] Winters, M., Brauer, M., Setton, E.M. and Teschke, K. (2010) Built Environment Influences on Healthy Transportation Choices, Bicycling versus Driving. Journal of Urban Health, 87, 969-993. http://dx.doi.org/10.1007/s11524-010-9509-6

[12] Vandenbulcke, G., Degraeuwe, B., Meeusen, R. and Panis, L.I. (2011) Cycle Commuting in Belgium, Spatial Determinants and "Re-Cycling" Strategies. Transportation Research Part A: Policy and Practice, 45, 118-137.

[13] Titze, S., Giles-Corti, B., Knuiman, M.W., et al. (2010) Associations between Intrapersonal and Neighborhood Environmental Characteristics and Cycling for Transport and Recreation in Adults, Baseline Results from the RESIDE Study. Journal of Physical Activity and Health, 7, 423-431.

[14] Nelson, A.C. and Allen, D. (1999) If You Build Them, Commuters Will Use Them. Transportation Research: Part B, 1587, 79-83.

[15] Winters, M., Davidson, G., Kao, D. and Teschke, K. (2010) Motivators and Deterrents of Bicycling: Comparing Influences on Decisions to Ride. Transportation, 38, 153-168. http://dx.doi.org/10.1007/s11116-010-9284-y

[16] Emery, J., Crump, C. and Bors, P. (2003) Reliability and Validity of Two Instruments Designed to Assess the Walking and Bicycling Suitability of Sidewalks and Roads. American Journal of Health Promotion, 18, 38-46. http://dx.doi.org/10.4278/0890-1171-18.1.38

[17] Frank, L.D., Schmid, T.L., Sallis, J.F., et al. (2005) Linking Objectively Measured Physical Activity with Objectively Measured Urban Form: Findings from SMARTRAQ. American Journal of Preventive Medicine, 28, 117-125. http://dx.doi.org/10.1016/j.amepre.2004.11.001

[18] Hall, P. and Richard, A. (2010) HPE's Walkability Index-Quantifying the Pedestrian Experience. Proceedings of the ITE 2010 Technical Conference and Exhibit, Meeting Transportation's 21st Century Challenges, Savannah, 14-17 March 2010, 26. 
[19] Owen, N., Cerin, E., Leslie, E., et al. (2007) Neighborhood Walkability and the Walking Behavior of Australian Adults. American Journal of Preventive Medicine, 33, 387-395. http://dx.doi.org/10.1016/j.amepre.2007.07.025

[20] Van Dyck, D., Cardon, G., Deforche, B., et al. (2010) Neighborhood Walkability and Sedentary Time in Belgian Adults. American Journal of Preventive Medicine, 39, 25-32. http://dx.doi.org/10.1016/j.amepre.2010.03.004

[21] Giles-Corti, B., Wood, G., Pikora, T., et al. (2011) School Site and the Potential to Walk to School: The Impact of Street Connectivity and Traffic Exposure in School Neighborhoods. Health Place, 17, 545-550. http://dx.doi.org/10.1016/j.healthplace.2010.12.011

[22] Harkey, D., et al. (1998) Development of the Bicycle Compatibility Index: A Level of Service Concept. Final Report, University of North Carolina, North Carolina.

[23] Van Dyck, D., Cerin, E., Conway, T.L., et al. (2012) Perceived Neighborhood Environmental Attributes Associated with Adults' Transport-Related Walking and Cycling: Findings from the USA, Australia and Belgium. International Society of Behavioral Nutrition and Physical Activity, 9, 70. http://dx.doi.org/10.1186/1479-5868-9-70

[24] Winters, M., Brauer, M., Setton, E.M. and Teschke, K. (2013) Mapping Bikeability: A Spatial Tool to Support Sustainable Travel. Environment and Planning B: Planning and Design, 40, 865-883. http://dx.doi.org/10.1068/b38185

[25] Broach, J., Dill, J. and Gliebe, J. (2012) Where Do Cyclists Ride? A Route Choice Model Developed with Revealed Preference GPS Data. Transportation Research Part A: Policy and Practice, 46, 1730-1740. http://dx.doi.org/10.1016/j.tra.2012.07.005

[26] Aultman-Hall, L. (1997) Analysis of Bicycle Commuter Routes Using Geographic Information Systems: Implications for Bicycle Planning. Transportation Research Record, 1578, 102-110. http://dx.doi.org/10.3141/1578-13

[27] Dill, J. (2009) Bicycling for Transportation and Health: The Role of Infrastructure. Journal of Public Health Policy, 30, 95-110. http://dx.doi.org/10.1057/jphp.2008.56

[28] Charreire, H., Weber, C., Chaix, B., et al. (2012) Identifying Built Environmental Patterns Using Cluster Analysis and GIS: Relationships with Walking, Cycling and Body Mass Index in French Adults. International Society of Behavioral Nutrition and Physical Activity, 9, 59. http://dx.doi.org/10.1186/1479-5868-9-59 